\title{
Model Pengaruh Persepsi Terhadap Kepuasan dan Loyalitas Pemustaka di Perpustakaan Nasional Republik Indonesia \\ (Models Influence Perceptions to Satisfaction and Loyalty Library Users in National Library of The Republic of Indonesia) \\ Leli Tamara', M. Syamsun'2, Ma'mun Sarma ${ }^{3}$ \\ ${ }^{1}$ Mahasiswa Institut Pertanian Bogor \\ 2,3 Dosen Departemen Manajemen -Fakultas Ekonomi dan Manajemen IPB
}

Diterima/disetujui : 22 Maret 2014/ 9 April 2014

\begin{abstract}
Improvement of service quality should be done consistently. Services of the National Library of the Republic of Indonesia should be based on the principle of public service. Efforts to improve the service factor will help deliver satisfaction and value -added library. Therefore, this research aimed to analyze influence perceptions to satisfaction and loyalty library user's in National Library of The Republic of Indonesia. This research was conducted at the National Library of the Republic of Indonesia on closed access services. Methods of testing instruments used were SPSS Software 16.00 and hypothesis testing used structural equation modeling (SEM) by software SmartPLS 2.00. Characteristics of respondents predominantly female (68\%), aged 17-25 years (82\%), working as a student (79\%) and educated S1 (76 \%). Based on the analysis of SEM with PLS approach, we can see the influence of the six basic elements of the library (electronic resources, print publications, other services, technical facilities, library environment, human side) to the value, satisfaction and loyalty. The results showed, the other services have a significant influence with the value of the users in the National Library of the Republic of Indonesia. While the variables of human side, environmental and electronic library resources influenced to satisfaction in the National Library of Indonesia. While the value of users variables significantly influenced to loyalty in the National Library of the Republic of Indonesia. Therefore it can be concluded that not all of the basic elements of the library have influence to value, satisfaction and loyalty.
\end{abstract}

Keywords : quality of service, value, satisfaction, loyalty, partial least squares (PLS)

\section{PENDAHULUAN}

Pelayanan pada organisasi publik saat ini dihadapkan pada masyarakat yang memiliki kebutuhan dan kepentingan atas jasa publik. Berkembangnya tuntutan masyarakat yang menginginkan pelayanan yang baik secara langsung dan tidak langsung akan berdampak pada organisasi publik itu sendiri. Kualitas pelayanan telah menjadi salah satu isu penting dalam penyediaan layanan publik di Indonesia. Kesan buruknya pelayanan publik selama ini selalu menjadi citra yang melekat pada institusi penyedia layanan di Indonesia. Kebijakan negara dalam upaya peningkatan kualitas pelayanan harus dilakukan secara konsisten dengan melihat kebutuhan masyarakat. Perpustakaan Nasional Republik Indonesia memiliki peran strategis dalam peningkatan kualitas sumber daya manusia dengan menggiring masyarakat ke arah budaya gemar membaca dan pembentukan masyarakat pembelajar.

Organisasi berorientasi layanan telah mengidentifikasi pelanggan atau pengguna sebagai suara yang paling kritis dalam menilai kualitas layanan (Adeniran 2011). Oleh karena itu, Perpustakaan Nasional Republik Indonesia harus mampu memberikan layanan perpustakaan yang prima dan berorentasi pada kepentingan pemustaka. 
Menurut Adeniran (2011) Perpustakaan harus meningkatkan kualitas layanan mereka untuk memungkinkan mereka menghadapi tantangan dari ledakan informasi pada abad ke-21. Sesuai dengan visi Perpustakaan Nasional Republik Indonesia yaitu terdepan dalam informasi pustaka, menuju Indonesia gemar membaca, maka pengembangan perpustakaan saat ini harus diarahkan pada pembentukan loyalitas. Sistem layanan yang diterapkan di Perpustakaan Nasional Republik Indonesia salah satunya adalah sistem akses tertutup (closed access), hal ini tentu berdampak pada proses layanan di Perpustakaan Nasional Republik Indonesia. Begitu pentingnya layanan tersebut, sehingga sering dikatakan bahwa penampilan dan kinerja perpustakaan akan tercermin dalam layanan informasi (Sumekar 2011). Bagian layanan selalu berhubungan dengan pemustaka dan merupakan ujung tombak dari setiap kegiatan perpustakaan. Upaya perbaikan atau penyempurnaan terhadap faktor-faktor layanan akan dapat membantu memberikan kepuasan dan nilai tambah serta membawa citra baik bagi perpustakaan. Analisis Structural Equation Modeling (SEM) dilakukan karena dapat menerjemahkan hubungan variabel - variabel sosial yang umumnya bersifat tidak dapat diukur secara langsung (laten) (Supriyadi 2013). Melalui pendekatan model persamaan struktural memungkinkan dilakukannya pengukuran secara kuantitatif terhadap persepsi, kepuasan dan loyalitas dari berbagai elemen dasar layanan perpustakaan (Martensen dan Gronholdt 2003). Dengan latar belakang tersebut, maka penelitian ini bertujuan untuk mengetahui pengaruh enam elemen dasar layanan perpustakaan terhadap kepuasan dan loyalitas pemustaka di Perpustakaan Nasional Republik Indonesia.

\section{METODOLOGI PENELITIAN}

Penelitian ini dilakukan di Perpustakaan Nasional Republik Indonesia layanan akses tertutup yaitu Layanan Koleksi Perpustakaan IImu Sosial dan Layanan Koleksi Perpustakaan IImu Terapan Perpustakaan Nasional Republik Indonesia. Penelitian dilakukan selama dua bulan yaitu pada bulan Januari sampai Februari 2014.

Jenis data yang dikumpulkan pada penelitian ini yaitu data primer dan data sekunder. Data primer pada penelitian ini adalah daftar pertanyaan untuk variabel sumberdaya elektronik, publikasi cetak, jasa layanan lain, fasilitas teknis, lingkungan perpustakaan, dan sisi manusia, nilai, kepuasan dan loyalitas. Sedangkan data sekunder yang diambil meliputi data pelayanan seperti jenis bahan pustaka, jumlah anggota perpustakaan dan jenis layanan. Data sekunder juga dilakukan dengan mempelajari buku-buku, internet, jurnal dan literatur yang berhubungan dengan penelitian.

Pengumpulan data yang dilakukan dengan memberikan kuesioner kepada pemustaka yanng terpilih sebagai responden. Kuesioner yang diberikan telah di Uji Validitas dan Uji Reliabilitas terlebih dahulu dan menunjukkan hasil yang valid dan reliable. Teknik pengambilan sampel yang digunakan purposive sampling yang merupakan metode penetapan sampel dengan berdasarkan pada kriteria-kriteria tertentu. Jumlah responden dalam penelitian ini adalah 100 orang. Skala pengukuran pada penelitian ini menggunakan skala numerical scale dengan skor 1-5. Pengolahan data pada penelitian ini menggunakan software Statistical Product and Service Solution (SPSS) versi 16 dan Smart PLS (Part Least Square) versi 2.0.

\section{Model Analisis}

Model pengaruh pada penelitian ini diadopsi dari penelitian Martensen dan Gronholdt tahun 2003 tentang kepuasan dan loyalitas melalui 9 variabel laten (Tabel 1). Melalui enam elemen dasar layanan perpustakaan (sumber daya elektronik, publikasi cetak, layanan lain, fasilitas teknik, lingkungan perpustakaan dan sisi manusia) kita dapat melihat pengaruh persepsi terhadap nilai, kepuasan dan loyalitas pemustaka. 
Tabel 1. Pengukuran Variabel

\begin{tabular}{|c|c|c|}
\hline $\begin{array}{l}\text { Variabel } \\
\text { Laten }\end{array}$ & \multicolumn{2}{|r|}{ Variabel Manifest (Indikator) } \\
\hline $\begin{array}{l}\text { Sumber Daya } \\
\text { Elektronik }\end{array}$ & SE1 & $\begin{array}{l}\text { Bagaimana keadaan sumberdaya elektronik, seperti } \\
\text { website, jurnal online, dan catalog online yang dimiliki oleh } \\
\text { Perpustakaan Nasional Republik Indonesia? }\end{array}$ \\
\hline & SE2 & $\begin{array}{l}\text { Apakah sumberdaya elektronik tersebut sesuai dengan } \\
\text { harapan dan dapat memenuhi kebutuhan pencarian Anda? }\end{array}$ \\
\hline \multirow[t]{2}{*}{$\begin{array}{l}\text { Publikasi } \\
\text { Cetak }\end{array}$} & PC1 & $\begin{array}{l}\text { Bagaimana kondisi koleksi publikasi cetak, seperti buku, } \\
\text { kumpulan hasil penelitian, data-data negara, jurnal tercetak, } \\
\text { majalah, dan surat kabar yang dimiliki Perpustakaan } \\
\text { Nasional Republik Indonesia? }\end{array}$ \\
\hline & PC2 & $\begin{array}{l}\text { Apakah koleksi publikasi cetak tersebut sesuai dengan } \\
\text { harapan dan dapat memenuhi kebutuhan pencarian Anda? }\end{array}$ \\
\hline \multirow[t]{4}{*}{ Layanan Lain } & LL1 & $\begin{array}{l}\text { Menurut Anda, apakah layanan perpustakaan digital tanpa } \\
\text { biaya yang telah disediakan oleh Perpustakaan Nasional } \\
\text { Republik Indonesia, seperti layanan akses jurnal dan hasil } \\
\text { penelitian, merupakan salah satu fasilitas perpustakaan } \\
\text { lainnya yang dapat mendukung kebutuhan Anda? }\end{array}$ \\
\hline & LL2 & Menurut Anda, apakah kegiatan yang telah dilakukan oleh \\
\hline & & $\begin{array}{l}\text { Perpustakaan Nasional Republik Indonesia, seperti } \\
\text { sosialisasi perpustakaan digital, dan pembaharuan hasil- } \\
\text { hasil penelitian secara berkala, dll merupakan salah satu } \\
\text { layanan perpustakaan lainnya yang dapat mendukung } \\
\text { kebutuhan Anda? }\end{array}$ \\
\hline & LL3 & $\begin{array}{l}\text { Apakah kualitas program dan kegiatan Perpustakaan } \\
\text { Nasional Republik Indonesia tergolong tinggi? }\end{array}$ \\
\hline \multirow[t]{2}{*}{$\begin{array}{l}\text { Fasilitas } \\
\text { Teknik }\end{array}$} & FT1 & $\begin{array}{l}\text { Bagaimana keadaan fasilitas teknis, seperti komputer dan } \\
\text { mesin fotocopy di Perpustakaan Nasional Republik } \\
\text { Indonesia? }\end{array}$ \\
\hline & FT2 & $\begin{array}{l}\text { Apakah fasilitas teknis tersebut sesuai dengan harapan dan } \\
\text { dapat memenuhi kebutuhan Anda? }\end{array}$ \\
\hline \multirow[t]{2}{*}{$\begin{array}{l}\text { Lingkungan } \\
\text { Perpustakaan }\end{array}$} & LP1 & $\begin{array}{l}\text { Bagaimana desain perpustakaan, kenyamanan, dan } \\
\text { peraturan yang diterapkan di Perpustakaan Nasional } \\
\text { Republik Indonesia? }\end{array}$ \\
\hline & LP2 & $\begin{array}{l}\text { Apakah desain perpustakaan, kenyamanan, dan peraturan } \\
\text { yang diterapkan di Perpustakaan Nasional Republik } \\
\text { Indonesia sesuai dengan harapan Anda? }\end{array}$ \\
\hline \multirow[t]{5}{*}{$\begin{array}{l}\text { Sumber Daya } \\
\text { Manusia }\end{array}$} & SM1 & $\begin{array}{l}\text { Bagaimana kecepatan pelayanan pustakawan dan petugas } \\
\text { perpustakaan di Perpustakaan Nasional Republik Indonesia } \\
\text { dalam melayani pemustaka? }\end{array}$ \\
\hline & SM2 & $\begin{array}{l}\text { Bagaimana kehandalan pelayanan pustakawan dan } \\
\text { petugas perpustakaan di Perpustakaan Nasional Republik } \\
\text { Indonesia dalam melayani pemustaka? }\end{array}$ \\
\hline & SM3 & Bagaimana keramahan pelayanan karyawan di \\
\hline & & $\begin{array}{l}\text { Perpustakaan Nasional Republik Indonesia dalam melayani } \\
\text { pemustaka? }\end{array}$ \\
\hline & SM4 & $\begin{array}{l}\text { Apakah pelayanan yang diberikan oleh karyawan di Bidang } \\
\text { Layanan Koleksi Khusus Perpustakaan Nasional Jakarta }\end{array}$ \\
\hline
\end{tabular}




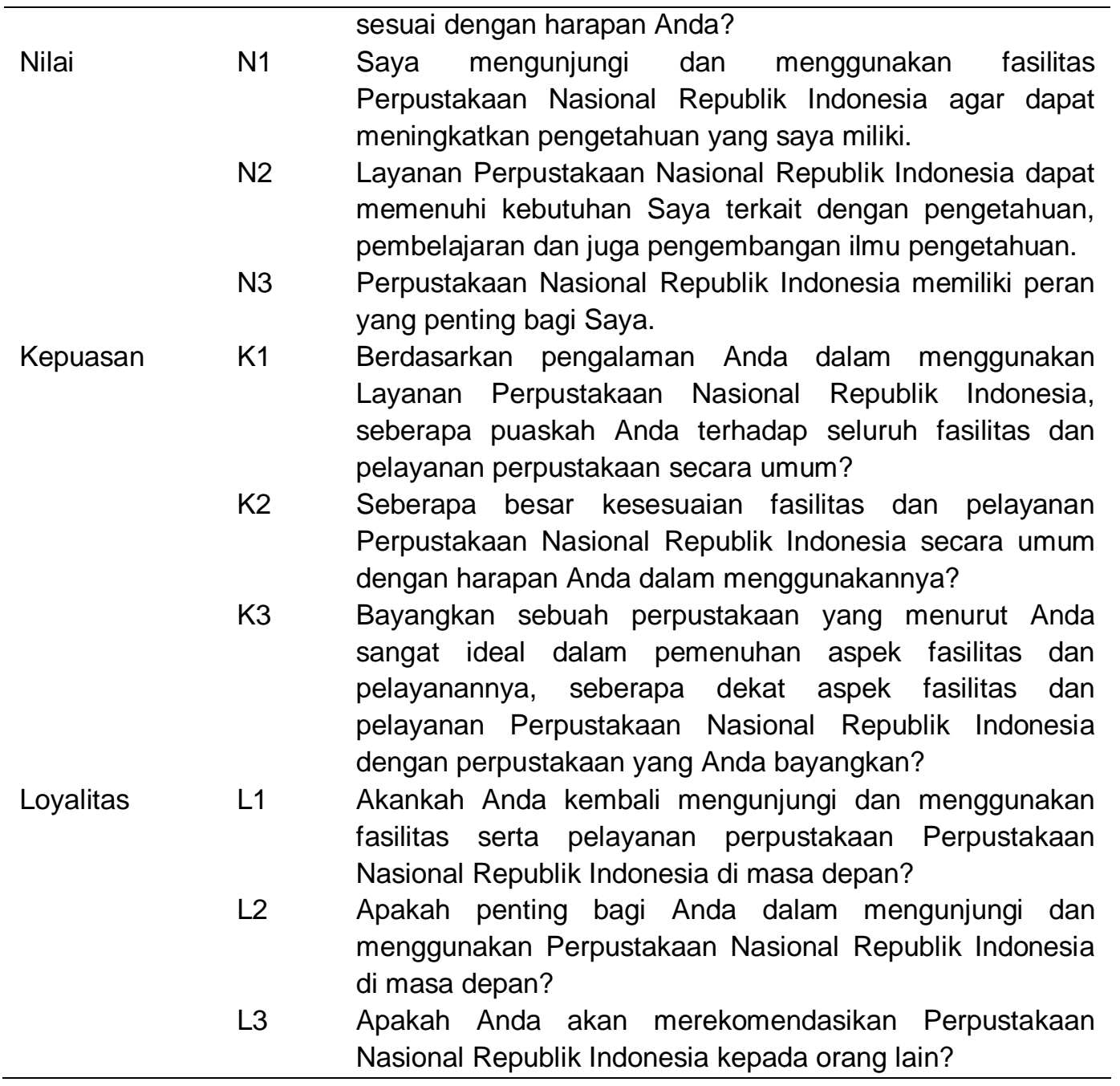

1) Analisis model outer

Menurut Wiyono (2011), uji outer model (uji indikator) menghasilkan empat output yaitu convergent validity, discriminant validity, average variance extracted (AVE) dan composite reliability. Convergent validity dapat dilihat dari niali loading faktor 0.50 sampai 0.6 sudah dianggap cukup. Discriminant validity menunjukkan nilai korelasi indikator dengan konstruk first order. Sebagai contoh, jika indikator-indikator struktur memang mengambarkan refleksi dari konstruk first order struktur, maka nilai korelasi indikator-indikator tersebut haruslah lebih besar dibandingkan korelasi indikator-indikator tersebut pada konstruk first order lainnya. Nilai average variance extracted (AVE), masing-masing variabel sudah memiliki nilai diatas 0.5 . Sedangkan composite reliability pada hasil analisis outer model masing-masing memiliki nilai lebih dari 0.7 .

2) Analisis model inner

Menurut Wiyono (2011), uji model untuk inner model (uji hipotesis) menghasilkan dua output yaitu $R$-Square untuk variabel laten endogen dan koefisien parameter dan TStatistik. Nilai $R$-Square sebesar 0.67 ; 0.33 ; dan 0.19 mengindikasikan bahwa model "Baik", "Moderat", dan "Lemah". Sedangkan analisis bootstrapping pada path coefficients, yaitu dengan membandingkan thitung dengan tabel. Jika nilai thitung $>$ tabel (1.96) maka perumusan hipotesis diterima, namun jika nilai thitung $<$ tabel (1.96) maka perumusan hipotesis ditolak.

Hipotesis pada penelitian ini yaitu : 
Hipotesis $1 \quad$ : Fasilitas teknik berpengaruh signifikan secara langsung terhadap kepuasan di Perpustakaan Nasional Republik Indonesia.

Hipotesis 2 : Kepuasan berpengaruh signifikan secara langsung terhadap loyalitas di Perpustakaan Nasional Republik Indonesia.

Hipotesis 3 : Layanan lain berpengaruh signifikan secara langsung maupun tidak langsung terhadap kepuasan di Perpustakaan Nasional Republik Indonesia.

Hipotesis 4 : Layanan lain berpengaruh signifikan secara langsung terhadap nilai di Perpustakaan Nasional Republik Indonesia.

Hipotesis 5 : Lingkungan perpustakaan berpengaruh signifikan secara langsung maupun tidak langsung terhadap kepuasan di Perpustakaan Nasional Republik Indonesia.

Hipotesis 6 : Lingkungan perpustakaan berpengaruh signifikan secara langsung terhadap nilai di Perpustakaan Nasional Republik Indonesia.

Hipotesis 7 : Nilai berpengaruh signifikan secara langsung kepuasan di Perpustakaan Nasional Republik Indonesia.

Hipotesis 8 : Nilai berpengaruh signifikan secara langsung maupun tidak langsung terhadap loyalitas di Perpustakaan Nasional Republik Indonesia.

Hipotesis 9 : Publikasi cetak berhubungan signifikan secara langsung maupun tidak langsung terhadap kepuasan di Perpustakaan Nasional Republik Indonesia.

Hipotesis 10 : Publikasi cetak berpengaruh signifikan secara langsung maupun tidak langsung terhadap loyalitas di Perpustakaan Nasional Republik Indonesia.

Hipotesis 11 : Publikasi cetak berpengaruh signifikan secara langsung terhadap nilai di Perpustakaan Nasional Republik Indonesia.

Hipotesis 12 : Sisi manusia berpengaruh signifikan secara langsung maupun tidak langsung terhadap kepuasan di Perpustakaan Nasional Republik Indonesia.

Hipotesis 13 : Sisi manusia berpengaruh signifikan secara langsung maupun tidak langsung terhadap loyalitas di Perpustakaan Nasional Republik Indonesia.

Hipotesis 14 : Sisi manusia berpengaruh signifikan secara langsung terhadap nilai di Perpustakaan Nasional Republik Indonesia.

Hipotesis 15 : Sumberdaya elektronik berpengaruh signifikan secara langsung terhadap kepuasan di Perpustakaan Nasional Republik Indonesia.

Hipotesis 16 : Sumberdaya elektronik berpengaruh signifikan secara langsung maupun tidak langsung terhadap loyalitas di Perpustakaan Nasional Republik Indonesia.

Hipotesis 17 : Sumberdaya elektronik berpengaruh signifikan secara langsung terhadap nilai di Perpustakaan Nasional Republik Indonesia.

\section{Analisis Outer Model}

\section{HASIL DAN PEMBAHASAN}

Reliabilitas indikator dicerminkan dari nilai loading yang merefleksikan kekuatan interelasi antara konstruk first order terhadap indikatornya. Nilai loading faktor untuk semua indikator di atas 0.5 menunjukkan indikator-indikator yang merefleksikan konstruk first order (Gambar 1). Oleh karena itu uji terhadap indikator dinyatakan semuanya valid karena nilai loading faktornya diatas 0.5 . 
Discriminant validity menunjukkan nilai korelasi indikator dengan konstruk first order. Berdasarkan nilai cross loading variabel sumberdaya elektronik, publikasi cetak, jasa layanan lain, fasilitas teknis, lingkungan perpustakaan, sisi manusia, nilai, kepuasan dan loyalitas, masing-masing sudah lebih besar dibandingkan indikator variabel lainnya. Artinya, jika indikator dari masing-masing variabel tersebut lebih besar dibandingkan dengan korelasi terhadap variabel laten yang lain maka indikator-indikator tersebut mereflektifkan variabel latennya.

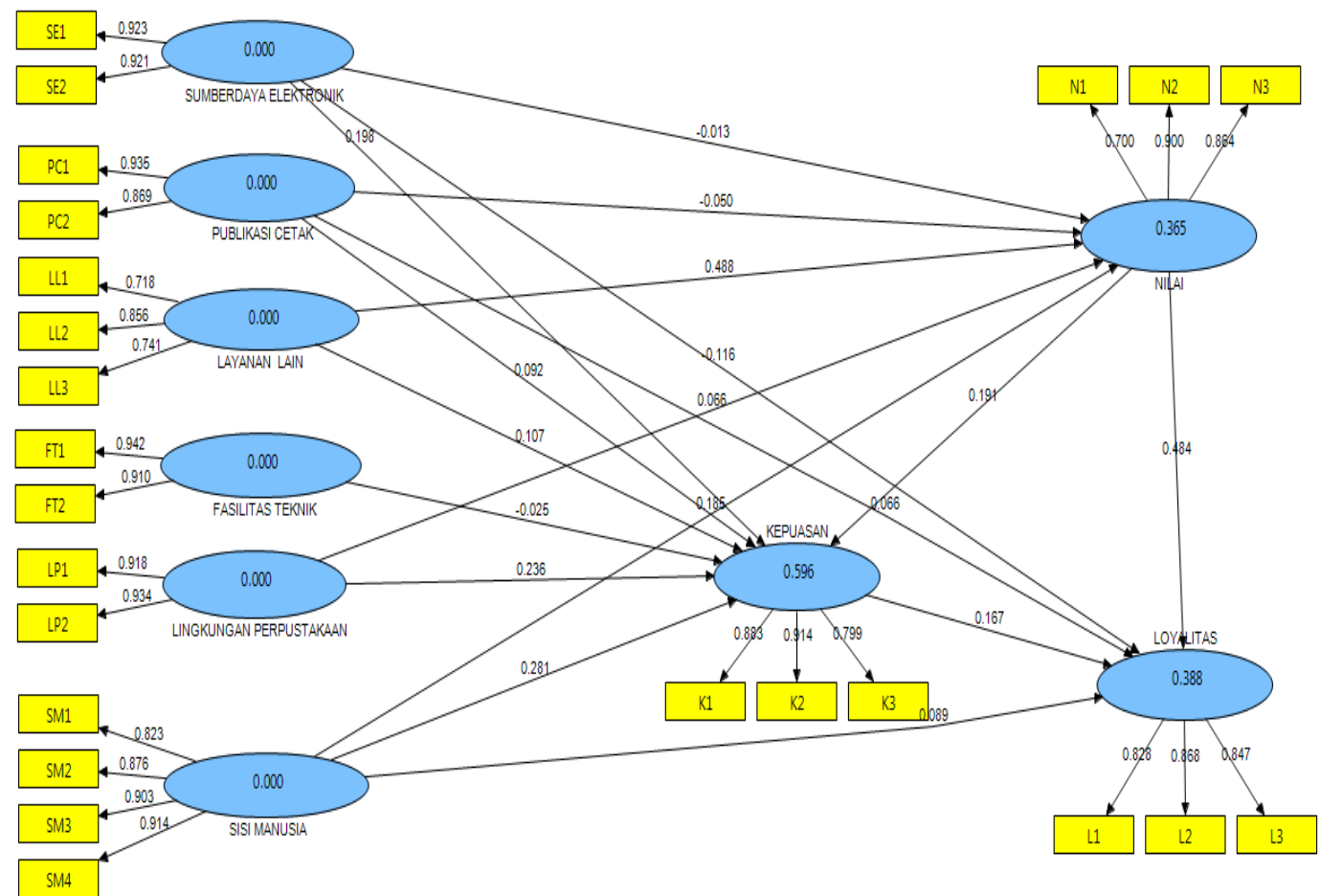

(Sumber : data primer yang diolah smart PLS 2.02014 )

Gambar 1. Hasil Outer Model

Nilai average variance extracted (AVE), masing-masing variabel sudah memiliki nilai diatas 0.5 (Tabel 1). Sedangkan berdasarkan nilai composite reliability pada hasil analisis outer model masing-masing memiliki nilai lebih dari 0.7. Berdasarkan hasil analisis yang diperoleh dari smart PLS menunjukkan bahwa semua variabel memiliki nilai reliabilitas komposit yang baik (Tabel 2).

Tabel 2. Nilai average variance extracted (AVE) dan composite reliability

\begin{tabular}{lcc}
\hline \multicolumn{1}{c}{ Variabel } & $\begin{array}{c}\text { Average variance } \\
\text { extracted (AVE) }\end{array}$ & Composite Reliability \\
\hline Fasilitas Teknik & 0.8578 & 0.9234 \\
Kepuasan & 0.7508 & 0.9001 \\
Layanan Lain & 0.5990 & 0.8166 \\
Lingkungan Perpustakaan & 0.8575 & 0.9233 \\
Loyalitas & 0.7186 & 0.8845 \\
Nilai & 0.6819 & 0.8641 \\
Publikasi Cetak & 0.8150 & 0.8980 \\
Sisi Manusia & 0.7739 & 0.9318 \\
\hline
\end{tabular}




\begin{abstract}
Sumberdaya Elektronik $\quad 0.8500 \quad 0.9189$
(Sumber : data primer yang diolah smart PLS 2014)

\section{Analisis Inner Model}

Hasil penelitian menunjukkan nilai $R$-Square dari masing-masing variabel laten endogen yaitu kepuasan sebesar 0.5958 , loyalitas sebesar 0.3877 dan nilai sebesar 0.3646. Hal ini mengindikasikan bahwa model "Moderat". Berbeda dengan hasil penelitian Martensen dan Gronholdt (2003), yang menyatakan bahwa model ini sangat baik untuk kepuasan dan loyalitas dengan nilai $R$-Square 0.74 .

Pengujian hipotesis dilakukan dengan melihat analisis bootstrapping pada path coefficients, yaitu dengan membandingkan thitung dengan tabel (Tabel 3). Jika nilai thitung $>$ tabel (1.96) maka perumusan hipotesis diterima, namun jika nilai thitung $<$ tabel $(1.96)$ maka perumusan hipotesis ditolak.

Tabel 3. Nilai path coefficients (thitung) dan hasil pengujian hipotesis
\end{abstract}

\begin{tabular}{|c|c|c|}
\hline Variabel & T-Hitung & $\begin{array}{c}\text { Hasil } \\
\text { Pengujian } \\
\text { Hipotesis }\end{array}$ \\
\hline Fasilitas Teknik -> Kepuasan & 0.3332 & Ditolak \\
\hline Kepuasan -> Loyalitas & 1.5428 & Ditolak \\
\hline Layanan Lain -> Kepuasan & 1.0017 & Ditolak \\
\hline Layanan Lain -> Nilai & 5.2303 & Diterima \\
\hline Lingkungan Perpustakaan -> Kepuasan & 2.5774 & Diterima \\
\hline Lingkungan Perpustakaan -> Nilai & 0.5356 & Ditolak \\
\hline Nilai -> Kepuasan & 1.7472 & Ditolak \\
\hline Nilai -> Loyalitas & 6.1027 & Diterima \\
\hline Publikasi Cetak -> Kepuasan & 1.1938 & Ditolak \\
\hline Publikasi Cetak -> Loyalitas & 0.6743 & Ditolak \\
\hline Publikasi Cetak -> Nilai & 0.5118 & Ditolak \\
\hline Sisi Manusia -> Kepuasan & 2.5115 & Diterima \\
\hline Sisi Manusia -> Loyalitas & 0.7375 & Ditolak \\
\hline Sisi Manusia -> Nilai & 1.8519 & Ditolak \\
\hline Sumberdaya Elektronik -> Kepuasan & 2.6684 & Diterima \\
\hline Sumberdaya Elektronik -> Loyalitas & 1.3009 & Ditolak \\
\hline Sumberdaya Elektronik -> Nilai & 0.1423 & Ditolak \\
\hline
\end{tabular}

(Sumber : data primer yang diolah smart PLS 2.0 2014)

Berdasarkan nilai t-statistik, hipotesis yang diterima pada model ini yaitu Hipotesis 4, Hipotesis 5, Hipotesis 8, Hipotesis 12 dan Hipotesis 15. Oleh karena itu terdapat empat 
elemen dasar perpustakaan (sumberdaya elektronik, layanan lain, lingkungan perpustakaan dan sisi manusia) yang berpengaruh secara langsung maupun tidak langsung terhadap dengan nilai, kepuasan dan loyalitas. Menurut Kotler dan Keller (2009a), kualitas merupakan kunci menciptakan nilai dan kepuasan pelanggan. Oleh karena itu berdasarkan hasil penelitian ini, nilai dan kepuasan pemustaka dapat dibangun melalui peningkatan kualitas elemen dasar perpustakaan di Perpustakaan Nasional Republik Indonesia.

Layanan lain berpengaruh signifikan secara langsung terhadap variabel nilai di Perpustakaan Nasional Republik Indonesia. Layanan lain ini berupa layanan akses jurnal dan hasil penelitian serta sosialisasi kegiatan dapat membantu peningkatan nilai bagi pengguna. Menurut Kotler dan Keller (2009a), nilai yang dipersepsikan pelanggan adalah selisih antara penilaian pelanggan prospektif atas semua manfaat dan biaya dari suatu penawaran terhadap alternatifnya.

Lingkungan perpustakaan berpengaruh signifikan secara langsung maupun tidak langsung terhadap kepuasan di Perpustakaan Nasional Republik Indonesia. Lingkungan perpustakaan ini berkaitan dengan desain perpustakaan, kenyamanan, dan peraturan yang diterapkan. Hal ini dapat diperkuat dari aspek warna dinding, pencahayaan yang sesuai, dan penandaan hal penting untuk mempersingkat waktu layanan (Kotler dan Keller 2009b).

Nilai berpengaruh signifikan secara langsung maupun tidak langsung terhadap loyalitas di Perpustakaan Nasional Republik Indonesia. Hal ini tentu saja menjadi penting karena dalam jangka panjang Perpustakaan Nasional Republik Indonesia harus membentuk loyalitas agar tercapai visi perpustakaan. Loyalitas pelanggan sangat penting artinya bagi perusahaan yang menjaga kelangsungan usahanya maupun kelangsungan kegiatan usahanya. Pada tahap berikutnya pelanggan yang loyal tersebut akan memperluas "kesetiaan" mereka pada produk - produk lain buatan produsen yang sama, dan akhirnya mereka adalah konsumen yang setia pada produsen atau perusahaan tertentu untuk selamanya (Mardikawati dan Farida 2013).

Sisi manusia berpengaruh signifikan secara langsung maupun tidak langsung terhadap kepuasan di Perpustakaan Nasional Republik Indonesia. Kepuasan adalah perasaan senang atau kecewa seseorang yang timbul karena membandingkan kinerja yang dipersepsikan produk terhadap ekspektesi mereka (Kotler dan Keller 2009a). Menurut Sumekar (2011), layanan perpustakaan akan maksimal jika didukung oleh sumber daya manusia yang memadai dan memiliki kompetensi yang dibutuhkan dalam melayani pemustaka. Selain itu variabel sumberdaya elektronik juga berpengaruh signifikan secara langsung terhadap kepuasan di Perpustakaan Nasional Republik Indonesia. Hal ini sangat membantu pemustaka dalam menemukan bahan pustaka yang diinginkan secara cepat mengingat sistem layanan yang digunakan adalah akses tertutup. Penggunaan Online Public Access Catalogue (OPAC) lebih cepat dibandingkan dengan cara manual dalam pencarian bahan pustaka sehingga menghemat waktu pencarian (Kumar dan Vohra 2013).

Tidak adanya pengaruh variabel publikasi cetak mungkin disebabkan kurang sadarnya responden terhadap pentingnya publikasi cetak bagi suatu perpustakaan. Sedangkan tidak adanya hubungan fasilitas teknik mungkin disebabkan sudah lengkapnya fasilitas yang dimiliki oleh Perpustakaan Nasional Republik Indonesia. Selain itu, hal ini dapat disebabkan oleh sistem layanan perpustakaan yang diterapkan yaitu akses tertutup yang lebih menitikberatkan pada aspek sumberdaya elektronik dan sumberdaya manusia.

Berdasarkan nilai $R$-Square untuk nilai, kepuasan dan loyalitas masing - masing adalah sebesar $0.3646 ; 0.5958$ dan 0.3877 . Artinya, nilai dipengaruhi oleh layanan lain 
sebesar $36.46 \%$ dan $63.54 \%$ dipengaruhi oleh faktor lain. Selanjutnya kepuasan dipengaruhi oleh sumberdaya elektronik, lingkungan perpustakaan dan sisi manusia sebesar $59.58 \%$ dan $40.42 \%$ dipengaruhi oleh faktor lain. Sedangkan untuk loyalitas dipengaruhi oleh nilai sebesar $38.77 \%$ dan $61.62 \%$ dipengaruhi oleh faktor lain.

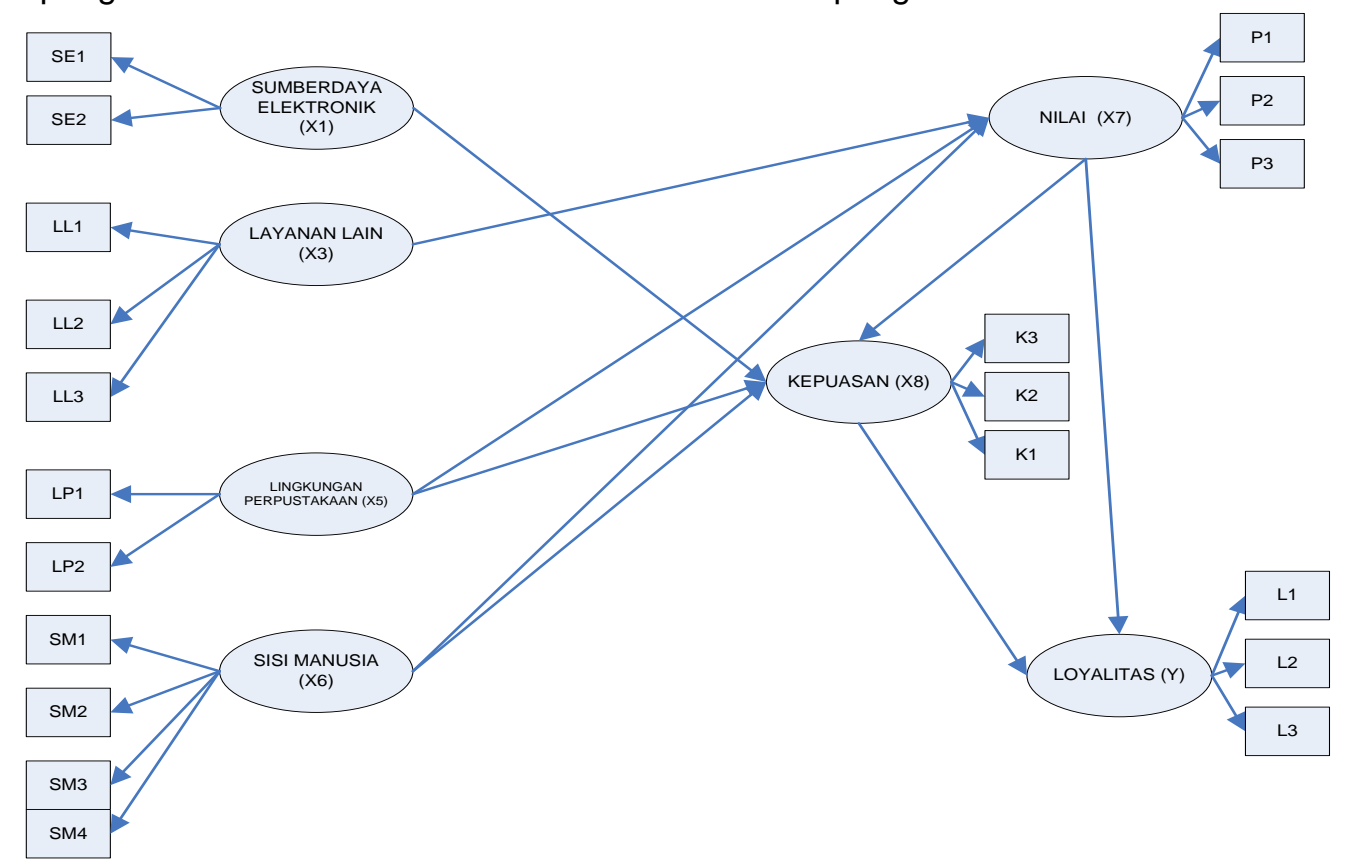

Gambar 2. Hasil Model Pengujian Hipotesis

\section{Implikasi manajerial}

Implikasi manajerial yang dapat dilakukan terhadap nilai pengguna, kepuasan dan loyalitas pemustaka di Perpustakaan Nasional Republik Indonesia yaitu melalui peningkatan kualitas layanan perpustakaan pada dimensi sumberdaya elektronik, layanan lain, lingkungan perpustakaan dan sisi manusia.

Peningkatan layanan lain di Perpustakaan Nasional Republik Indonesia dapat meningkatkan nilai pengguna terkait dengan pengetahuan, pembelajaran dan pengembangan ilmu pengetahuan. Layanan lain ini dapat berupa peningkatan akses jurnal, hasil penelitian, sosialisasi keanggotaan, sosialisasi prosedur layanan, sosialisasi kegiatan maupun program perpustakaan.

Peningkatan kepuasan pemustaka di Perpustakaan Nasional Republik Indonesia dapat dilakukan melalui sumberdaya elektronik, lingkungan perpustakaan dan sisi manusia. Sumberdaya elektronik dapat ditingkatkan melalui peningkatan kualitas catalog online. Kualitas lingkungan perpustakaan dapat ditingkatkan melalui desain perpustakaan, kenyamanan dan peraturan yang diterapkan oleh Perpustakaan Nasional Republik Indonesia. Pada sisi manusia dapat ditingkatkan melalui kecepatan, kehandalan dan keramahan pelayanan oleh pustakawan dan staf perpustakaan.

Peningkatan dan pembentukan loyalitas pemustaka dapat dilakukan melalui peningkatan nilai pengguna melalui peningkatan layana lain. Semakin bernilainya suatu perpustakaan bagi pemustaka akan berdampak pada peningkatan loyalitas.

\section{SIMPULAN DAN SARAN}

Berdasarkan hasil analisa penelitian yang telah diuraikan, maka dapat disimpulkan bahwa :

1. Lingkungan perpustakaan, publikasi cetak, sisi manusia dan sumberdaya elektronik tidak berpengaruh terhadap nilai pengguna di Perpustakaan Nasional 
Republik Indonesia. Sedangkan layanan lain berpengaruh terhadap nilai pengguna di Perpustakaan Nasional Republik Indonesia.

2. Fasilitas teknik, layanan lain dan publikasi cetak tidak berpengaruh terhadap kepuasan di Perpustakaan Nasional Republik Indonesia. Sedangkan sisi manusia, lingkungan perpustakaan dan sumberdaya elektronik berpengaruh terhadap kepuasan di Perpustakaan Nasional Republik Indonesia.

3. Publikasi cetak, sisi manusia dan sumberdaya elektronik tidak berpengaruh terhadap loyalitas pemustaka di Perpustakaan Nasional Republik Indonesia.

4. Nilai pengguna tidak berpengaruh terhadap kepuasan pemustaka di Perpustakaan Nasional Republik Indonesia.

5. Nilai berpengaruh terhadap loyalitas di Perpustakaan Nasional Republik Indonesia.

6. Kepuasan tidak berpengaruh terhadap loyalitas di Perpustakaan Nasional Republik Indonesia.

Adapun untuk saran dalam penelitian ini adalah sebagai berikut:

1. Perpustakaan Nasional Republik Indonesia dapat meningkatkan nilai pengguna melalui peningkatan kualitas layanan lain

2. Perpustakaan Nasional Republik Indonesia dapat meningkatkan kepuasan melalui sisi manusia, lingkungan perpustakaan dan sumberdaya elektronik yang dimiliki oleh Perpustakaan Nasional Republik Indonesia.

3. Perpustakaan Nasional Republik Indonesia dapat meningkatkan loyalitas pemustaka melalui peningkatan nilai pengguna.

\section{DAFTAR PUSTAKA}

Adeniran Pauline. 2011. User Satisfaction with academic libraries service : academic staff and stsudents perspectives. International Journal of Library and Information Science [Internet]. [diunduh 2013 DEC 30]; 3(10) : 209-216; NG. Tersedia pada : http://www.academicjournals.org /journal/IJLIS/article-abstract/3BAFB0A4863

Kotler Philip, Keller Kevin Lane. 2009a. Manajemen Pemasaran Jilid 1. Jakarta : Erlangga.

Kotler Philip, Keller Kevin Lane. 2009b. Manajemen Pemasaran Jilid 2. Jakarta : Erlangga.

Kumar Shiv, Vohra Ranjana. 2013. User Perception and Use of OPAC: A Comparison of Three Universities in the Punjab Region of India. Emerald Group Publishing [Internet]. [diunduh 2014 APR 10]; 31(1): pp. 36-54; IN. Tersedia pada : http://eresources.pnri.go.id:2056/docview/1283392547

Mardikawati Woro, Farida Naili. 2013. Pengaruh Nilai Pelanggan dan Kualitas Layanan terhadap Loyalitas Pelanggan, melalui Kepuasan Pelanggan pada Pelanggan Bus Efisiensi (Studi PO Efisiensi Jurusan Yogyakarta-Cilacap). Jurnal Administrasi Bisnis [Internet]. [diunduh 2014 APR 10]; 2(1): 64-75; ID. Tersedia pada

http://www.google.co.id/url?q=http://ejournal.undip.ac.id/index.php/janis/article/do wnload/5355/4810

Martensen Anne dan Gronholdt Lars. 2003. Improving Library Users' Perceived Quality, Satisfaction and Loyalty: An Integrated Measurement and Management System. The Journal of Academic Librarianship [Internet]. [diunduh 2013 JUN 3]; 29(3):140-147; DK. Dersedia pada http://cdigital.uv.mx/bitstream/123456789/5946/1/Usuarios.pdf. 
Sumekar Sri. 2011. Manajemen Pemasaran Perpustakaan. Jakarta : Perpustakaan Nasional Republik Indonesia.

Supriyadi Edy. 2013. Analisis Jalur dan Structural Equation Model. Jakarta : IN MEDIA.

Wiyono Gendro. 2011. Merancang Penelitian Bisnis dengan Alat Analisis SPSS17.00 dan Smart PLS 2.0. UPP STIM YKPN. Yogyakarta. 